\title{
Çeviri, yemek ve kültür ilişkisi: Altyazı çevirisinde kültüre özgü mutfak terimlerinin aktarımı
}

\section{Şule DEMİRKOL ERTÜRK1}

\begin{abstract}
APA: Demirkol Ertürk, Ş. (2020). Çeviri, yemek ve kültür ilişkisi: Altyazı çevirisinde kültüre özgü mutfak terimlerinin aktarımı. RumeliDE Dil ve Edebiyat Araştırmaları Dergisi, (18), 610-626. DOI: 10.29000/rumelide.706418
\end{abstract}

\section{$\ddot{\mathbf{O} z}$}

Yemek kavramı, sosyoloji ve antropoloji gibi sosyal bilim alanlarında çok daha uzun zamandır özel bir inceleme konusu olarak kendini göstermiş olsa da çeviribilim alanında bu konuya olan ilginin daha yakın bir tarihte ortaya çıktığı görülmektedir. Bu makalede, 2009 yılında Walt Disney tarafindan "The Princess and the Frog" başlı̆̆ıyla izleyiciye sunulan ve Türkçeye "Prenses ve Kurbağa” başlı̆̆ıla çevrilen filmin iki Türkçe altyazısı kültüre özgü mutfak terimlerinin çevirisine odaklanarak incelenmektedir. Ayrıca sevgi sözü olarak kullanılan yemek isimlerinin çevirisi ve içinde yemek isimleri geçen deyimlerin ve kalıp ifadelerin çevirisi de incelemeye alınmıştır. Yemek ve çeviri konusunda bir inceleme yapmak için bu filmin seçilmesinin nedeni, yemeğin filmdeki ana aktörlerden biri olmasıdır. Olay örgüsü New Orleans’ta geçen film, karakterleri ve kültürü anlatmak için Louisiana mutfağına özgü birçok yemekten yararlanmaktadır. Bu nedenle, Türk mutfağından oldukça farklı bir yapısı olan Louisiana mutfağına özgü mutfak terimlerinin, altyazı çevirisi gibi çok önemli teknik kısıtlamalar barındıran bir alanda nasıl aktarılacağı sorusu önem kazanır. İncelemede filmin çeviri açısından düşündürücü örnekler ortaya koyduğu görülmüştür. Ele alınan her iki çeviride de çevirmenlerin birden fazla çeviri yöntemini bir arada kullandığı anlaşılmıştır. Bu çevirilerde başvurulan yöntemler arasında ödünç alma, üst terim kullanarak genelleme yoluyla aktarma, açımlama, başka bir yemek ismiyle değiştirme ve atlama özellikle öne çıkmaktadır.

Anahtar kelimeler: Çeviribilim, yemek çevirisi, kültür ve çeviri, altyazı çevirisi, çizgi film çevirisi.

\section{Translation, food and culture: the transfer of culture-specific culinary terms in subtitles}

\begin{abstract}
Although the concept of food has been studied for a long time in social sciences such as sociology and anthropology, the interest in this concept is relatively new in Translation Studies. This article examines two different Turkish subtitles of the Walt Disney movie "The Princess and the Frog" released in 2009 and translated into Turkish as "Prenses ve Kurbağa", with special attention to the translation of culture-specific culinary terms. The analysis also covers the translation of food items used to express affection, together with those used in idioms and fixed expressions. The movie was chosen for this analysis because it foregrounds food as one of the main characters. The plot is set in New Orleans, and recipes from Louisiana cuisine play a significant role in the description of the characters and the culture. Considering the differences between Louisiana and Turkish cuisines, and keeping in mind the technical restrictions of subtitling, it remains to question how culinary terms
\end{abstract}

1 Dr. Öğr. Üyesi, Boğaziçi Üniversitesi, Fen Edebiyat Fakültesi, Ceviribilim Bölümü (İstanbul, Türkiye), sule.demirkol@boun.edu.tr, ORCID ID: oooo-0002-3557-5758 [Makale kayıt tarihi: 02.01.2020-kabul tarihi: 20.03.2020; DOI: 10.29000/rumelide.706418] 
specific to Louisiana cuisine can be transferred in Turkish subtitles. The analysis shows that the movie provides thought provoking examples regarding the translation of food related terms. It was observed that translators of both subtitles resorted to a variety of methods in dealing with the transfer of culinary terms. Among these methods, borrowing, generalization by use of a hypernym, paraphrase, substitution with a different food item and omission were the most visible ones.

Keywords: Translation studies, food translation, culture and translation, subtitling, animation subtitling.

\section{Giriş}

Son yıllarda çeviribilim alanında yapılan akademik çalışmalarda yemek ve çeviri konusuna özel bir ilgi gösterildiği dikkat çekmektedir. Yemek kavramı, sosyoloji ve antropoloji gibi sosyal bilim alanlarında çok daha uzun zamandır özel bir inceleme konusu olarak kendini göstermiş olsa da çeviribilim alanındaki ilginin daha yakın bir tarihte ortaya çıktığı gözlemlenmektedir. Delia Chiaro ve Linda Rossato (Chiaro \& Rossato, 2015), antropologların ve sosyologların, yemekle ilgili olguları betimlerken dilbilimden ve dilin anlam evreninden yararlandıklarını belirttikten sonra dilbilimcilerin ve çeviribilimcilerin bu konuyu uzun süre görmezden geldiklerini vurgular ve çeviribilimcilerin, kültürlerarası geçişlere dikkat eden özel konumları nedeniyle aslında bu konuyu çalışmak için ayrıcalıklı bir yerde durduklarını belirterek çeviribilimcileri bu alanda daha fazla inceleme yapmaya davet eder (Chiaro \& Rossato, 2015: 241). Bu makalede, 2009 yllında Walt Disney tarafindan "The Princess and the Frog” başlı̆̆ıyla izleyiciye sunulan ve Türkçeye "Prenses ve Kurbağa" başlığıyla çevrilen filmin iki farklı Türkçe altyazısı kültüre özgü yemek isimlerinin çevirisine odaklanarak incelenecektir. Yemek ve çeviri konusunda bir inceleme yapmak için bu filmin seçilmesinin nedeni, yemeğin filmdeki ana aktörlerden biri olması. Aşağıda da anlatılacağı gibi, olay örgüsü New Orleans'ta geçen film, karakterleri ve kültürü anlatmak için Louisiana mutfağına özgü birçok yemekten yararlanıyor. Yemek isimleri hem düz anlamlarıyla hem de sevgi sözü olarak ya da deyimlerin ve kalıp ifadelerin içinde film boyunca çok sık kullanılıyor. Bu nedenle, Türk mutfağından oldukça farklı bir yapısı olan Louisiana mutfağına özgü yemek isimlerinin, altyazı çevirisi gibi çok önemli teknik kısıtlamalar barındıran bir alanda nasıl aktarılacağı sorusu önem kazanıyor. İlerleyen sayfalarda, öncelikle yemek ve çeviri konusunda çeviribilim alanında yapılan güncel çalışmalar gözden geçirilecek ve daha sonra biri gönüllü olarak çevrilip internette paylaşılmış ve biri de filmin Türkiye'de satışa sunulan yasal kopyalarında kullanılan iki çeviri incelenerek çevirmenlerin yemekle ilgili ifadelerin çevirisinde başvurdukları ödünç alma, üst terim kullanarak genelleme yoluyla aktarma, açımlama, başka bir yemek ismiyle yer değiştirme ve atlama gibi yöntemler tartışılacaktır.

\section{Yemek ve çeviri}

Sosyal bilimler alanında yemek çalışmalarına gösterilen ilgi son yıllarda artmış olsa da bu alandaki çalışmalar çok daha eskiye dayanmaktadır ve Roland Barthes (1961), Pierre Bourdieu (1979) ve Claude Levi-Strauss (1966) gibi isimlerin bu alandaki incelemeleri öncü çalışmalar arasında anılmaktadır. Carole Counihan ve Penny Van Esterik, 200o'lerle birlikte yemek çalışmaları alanının hızla geliştiğini ve bu alandaki yayınların sayısının hızla arttığını belirtir (Counihan \& Van Esterik, 2013: 1). Beslenme, ev ekonomisi ve tarım gibi geleneksel olarak yemekle ilgilenen alanların yanı sıra felsefe, psikoloji, coğrafya, film çalışmaları ve mimarlık gibi alanlarda çalışan araştırmacıların da yemek konusuna gittikçe daha fazla ilgi gösterdiğini vurgular. Yemeğin, diaspora ve göç, milliyetçilik ve küreselleşme, yemek turizmi, toplumsal cinsiyet ve etnik kimlik, toplumsal adalet ve insan hakları, modernleşme ve 
değişen beslenme şekilleri gibi birçok farklı meseleyle bağlantılı olarak incelendiğini belirtir (Counihan \& Van Esterik, 2013: 1-2).

Küreselleşen dünyada yiyecekler ve yemek tarifleri de artık tüm dünyayı dolaşmaktadır. Bu nedenle yemekle ilgili metinlerin çevirisine duyulan ihtiyaç da her geçen gün artmaktadır. Yemek kitapları, turist rehberlerinin yemek bölümleri, televizyondaki yemek programları ve yemek içerikli web sayfaları günümüzde büyük ilgi görmektedir ve bu ilgiye paralel olarak da hızla farklı dillere çevirileri yapılmaktadır. Ancak çeviribilim alanında yemekle ilgili metinlerin çevirisi konusu uzun süre ihmal edilmiş ve sadece son yıllarda biraz daha ilgi çekmeye başlamıştır. Delia Chiaro ve Linda Rossato, 2015 yılında The Translator dergisi için hazırladıkları "Yemek ve Çeviri” başlıklı özel sayı için yazdıkları sunuş makalesinde, yemek metinlerinin çevirisiyle ilgili pazarın hızla büyümesine rağmen çeviribilim alanında bu konuda yapılan araştırmaların oldukça az olduğunu vurgular (Chiaro \& Rossato, 2015: 237). Ancak son yıllarda çeviribilim alanında da bu konuda yapılan çalışmaların hızla arttığı söylenebilir (örneğin Chiaro 2008; Chiaro \& Rossato 2015; Cronin 2015, 2017; De Marco 2015; González-Vera 2015; Rossato 2015; Oster \& Molés-Cases 2016; Stano 2016; Vidal Claramonte \& Faber 2017; Beyaz 2017; Ciribuco 2019).

Roland Barthes'in 1961 tarihli Pour une psycho-sociologie de l'alimentation contemporaine makalesinde ortaya koyduğu yaklaşım hem yemek çalışmaları alanını hem de çeviribilim alanında yemekle ilgili olarak yapılan incelemeleri önemli ölçüde etkilemiştir. Barthes'a göre yemek, bir "iletişim dizgesidir", bir “imgeler bütünüdür” (Barthes, 1961: 979). Kullanılan malzemeler, hazırlama yöntemleri ve yemekle ilgili alışkanlıkların hepsi farklı anlamlar üretir ve böylece yemek bir iletişim aracına dönüşür (Barthes, 1961: 980). Barthes'ın kurduğu çerçeveyi takip eden ve yemeği bir “iletişim dizgesi” olarak gören Linda Rossato'ya göre yemeği ve yemek kültürünü çevirmek de bütün bir anlam evrenini çevirmek demektir: "gelenekleri, toplumsal pratikleri, yemekle ilgili bilgi birikimini, toplumsal ayrışmayı, sinıfları, toplumsal cinsiyeti” ve bunlarla birlikte gelen birçok anlamı (Rossato, 2015: 275).

Giuliana Garzone de yemeğin gelenekle ve kimlikle ilişkisini ele alır ve özellikle kimliğini kaybetme korkusu yaşayan topluluklar için mutfak geleneklerinin korunmasının çok büyük önem taşıdığını vurgular (Garzone, 2017). Garzone’ye göre, asimetrik güç ilişkilerinin yaşandığı sömürgecilik sonrası bağlamlarda ya da entegrasyon ve asimilasyon meselelerinin gündeme geldiği göçle ilgili süreçlerde mutfak kültürünün canlı tutulması, geleneğin korunmasına yarayan bir araç olarak özel bir önem kazanır (Garzone, 2017: 217). Yine Barthes'ın görüsslerinden yola çıkan Garzone, yemeğin hem toplumsal statüye hem de toplumsal ve dinsel aidiyetlere dair bilgi verdiğini belirtir. Yemekle ilgili alışkanlıkların ulusal, bölgesel ve etnik bağlantılar kurduğunu ve farklı grupları birbirinden ayırt ettiğini hatırlatır (Garzone, 2017: 218). Yemek kültürlerinin ifade ettiği kimliklerin özellikle sömürgecilik-sonrası ve göçle ilgili bağlamlarda anlam kazandığını vurgular.

Garzone'nin odaklandığı asimetrik güç ilişkileri çeviribilim alanında da özellikle sömürgecilik sonrası çalışmalar çerçevesinde ele alınmıştır. Yemek ve çeviri konusu bağlamında ise $\mathrm{M}^{\mathrm{a}}$ Carmen África Vidal Claramonte ve Pamela Faber, (2017), sömürgecilik sonrası edebiyata odaklanarak, iki dilde ve iki kültürde yaşayan kadın yazarların romanlarında yemeğin bir gösterge dizgesi olarak rolünü inceler ve bu kadın yazarların yapıtlarında yemekle bağlantılı sözcükleri neden çevirmeden bıraktıklarını sorgular (Vidal Claramonte \& Faber, 2017: 193). Bu çerçevede yemeğin sadece hayatta kalmak için gerekli bir ihtiyaç olmayıp sömürülen tarafın kimliğini korumaya yarayan kültürel ve simgesel bir kaynak olduğunu ileri sürer (Vidal Claramonte \& Faber, 2017: 193). İnceledikleri kadın yazarların İngilizce yazdıkları romanlarda yemek isimlerini ana dillerinde bırakarak farklılıklarını ve "minör" bir topluluğa olan 
aidiyetlerini ifade ettiklerini savunur (Vidal Claramonte \& Faber, 2017: 193-194). Ayrica bu yolla dille ilgili politik bir tavır sergilediklerini ve kültürler arasındaki asimetriyi görünür kılarak tek dilliliğe karşı çlktıklarını iddia eder (Vidal Claramonte \& Faber, 2017: 199-200).

Yemek ve çeviri konusuna yine politik bir perspektifle yaklaşan Linda Rossato ise yemekle ilgili çevirilerdeki “kültürel sömürgeciliğe" dikkat çeker (Rossato 2015). Britanyalı şef Jamie Oliver'ın İtalyan mutfağı üzerine hazırladığı ve temelde Britanyalı izleyicileri hedefleyen televizyon programlarının ve yemek kitaplarının İtalyancaya çevirisini inceleyen Linda Rossato yemek televizyonculuğundaki patlamaya dikkat çeker. Bu alanda Britanya kökenli televizyon kanallarının başı çektiğini ve hazırladıkları programların pek çok dile çevrildiğini belirten Rossato, Britanyalı şeflerin dünyanın farklı bölgelerinden ulusal mutfakları yorumlayarak dünyaya tanıtır konuma yerleştiklerini belirtir (Rossato, 2015: 272). Bunun sonucunda da Jamie Oliver gibi şeflerin aynı zamanda birer "çevirmen" gibi davrandıklarını ileri sürer (Rossato, 2015: 275). Ancak Rossato bu durumu tarafsız bir süreç olmaktan ziyade bir tür "kültürel sömürgecilik" olarak yorumlar (Rossato, 2015: 273).

Yemek ve çeviri üzerine yapılan çalışmalarda öne çıkan konulardan biri de yemek ve çeviri arasında yapilan benzetmelerdir. Chiaro ve Rossato, çeviri edimiyle yemek yapma arasındaki benzerliğe dikkat çeker (Chiaro \& Rossato, 2015: 238): Başka bir kültüre ait bir yemeği hazırlama işine koyulan aşçı da başka bir dildeki bir metni yeni bir dile aktarmaya koyulan çevirmen gibi birçok karar vermek zorundadır. Her ikisi de öncelikle kaynak metni ya da yemeğin tarifini inceler, doğru malzemeleri ya da sözcükleri arar, hazırlayacakları yemeğin ya da çevirinin hedef kitlesini memnun etmek için hangi stratejileri kullanmak gerektiğini sorgular. Bu çerçevede bazen bir malzemeyi ya da bir ifadeyi dışarıda bırakmaları ya da başka bir malzeme ya da ifadeyle değiştirmeleri, bir sözcüğü açıklamaları ya da bir pişirme yöntemini tarif etmeleri gerekebilir (Chiaro \& Rossato, 2015: 238).

Chiaro ve Rossato, farklı mutfaklara özgü malzemeleri bir araya getiren, örneğin Akdeniz tatlarıyla Doğu baharatlarını karıştıran "füzyon" mutfağını da çeviriye benzetir. "Çeviri” yemeklere örnek olarak da Pizza Hut'ın jambonla ananası yan yana getiren Hawaii Pizzası gibi ürünleri anar (Chiaro \& Rossato, 2015: 238). Fakat yemek kültürü, kültürel kimliğimizin ve kültür hafızamızın önemli bir parçası olduğu için geleneksel yemeklerin tarifleriyle fazla oynanması tepkilere de sebep olabilir çünkü yine Chiaro ve Rossato'nun da belirttiği gibi, özgün tariflere bağlı olanlar, çocukluklarından beri severek yedikleri yemeklerin bu yeni versiyonlarını reddedebilir. Başka bir deyişle, tıpkı şiir ya da mizah çevirisinde olduğu gibi bu yemeklerinin "çevrilemez" olduğunu düşünebilirler (Chiaro \& Rossato, 2015, 239). Yine de şiir ve mizahta olduğu gibi yemek tarifleri de her zaman çevrilmeye devam etmektedir.

Michael Cronin de çeviri ve yemek arasında bir benzetme yapar. Claudia Roden'e atıfla yemeğin sadece beslenmeyle ve yemek pişirmeyle sınırlı olmadığını, yemeğin bir dili olduğunu hatırlatır (Cronin, 2015: 244) ve buradan hareket ederek, yer değiştiren yemeğin yine dil aracıllğıyla yer değiştireceğini belirtir. $\mathrm{Bu}$ nedenle de yemeğin farklı kültürler içinde nasıl değiştiğini anlamak için çeviriye de bakmamız gerekeceğini vurgular (Cronin, 2015: 245). Michael Cronin, bu bağlamda "yavaş dil” kavramını ortaya atar (Cronin, 2015; 2017). Hem çeviri hem de yemek konusunda son dönemde hizla artan talep karşısında, çeviri sektöründe geliştirilen otomatik çeviri yöntemlerini ve gıda sektöründe öne çıkan yüksek miktarlarda üretime ve hızlı tüketime yönelik uygulamaları birlikte değerlendirir. Bu hızlı tüketim zinciri karşısında yemek alanında son dönemlerde ortaya çıkan "Yavaş Yemek" hareketinin bir benzerinin çeviri için de söz konusu olup olamayacağını sorgular. Bu çerçevede, kendisiyle aynı soruyu soran ve bir "Yavaş Dil” hareketi çağrısında bulunan Marilyn Chandler McEntyre'a atıfla tıpkı su, toprak, hayvanlar ve bitki türleri gibi sözcüklerin de değerli ve paylaşlan kaynaklar olduğunu hatırlatır (Cronin 
2015, 248; McEntyre 2009 in Cronin 2015) ve McEntyre'ın çağrısını tekrarlar: "Birbirimizle paylaştığımız cümleleri 'pişirmek', 'yemek' ve sindirmek için, belki biz de Yavaş Yemek hareketi gibi bir Yavaş Dil hareketine ihtiyaç duyuyor olabiliriz”"2 (McEntyre, 2009: 83, alıntılayan Cronin, 2015: 249).

Bu çağrının izini süren Cronin, bu “yavaş dil” hareketinin nasıl şekilleneceğini zihnimizde canlandırmak için yemek çevirilerine bakabileceğimizi ileri sürer ve yemek çevirisinin, yeni bir çeviri ekolojisi yaratmak için son derece önemli bir rol oynayabileceğini belirtir (Cronin, 2015: 249). Cronin’e göre, yemeklerde kullanılan malzemeler çok çeşitli olduğu ve farklı kültürlerde birbirine benzer ancak yine de farklı ürünler bulunduğu için bir tek malzemenin ismini çevirmek için bile durup düşünmemiz, benzer ürünlerin tanımlarına bakmamız ve farklı kültürlerdeki ürünleri kıyaslamamız gerekir. Bu da yavaşlamak demektir (Cronin, 2015: 249). Öte yandan, yemek çevirisi yapmak için yemeğin üretildiği ve tüketildiği yerin ve ortamın anlamını da kavramak gerekir (Cronin, 2015: 249). Yemekle ilgili ritüellerin ve bunların yerel kültürle olan ilişkisinin edebiyattaki yansımalarını anlamak ve çevirmek için yöreyi tanımak, toplumsal süreçleri kavramak gerekir ve bu da yine zaman gerektirir. Sofraya konan yemeğin tüm anlamını kavramak ancak bu şekilde mümkün olabilir (Cronin, 2015: 249-250).

\section{“Prenses ve Kurbağa” filminin öne çıkan özellikleri}

2009 yllında, Walt Disney tarafından "The Princess and the Frog” başlı̆̆ıyla izleyiciye sunulan film, Türkiye'de "Prenses ve Kurbağa” başlığıyla gösterime girmiştir. Grimm Kardeşler’in "Kurbağa Prens" ve Elizabeth Dawson Baker'ın "Kurbağa Prenses” adlı masallarından yola çıkan film, klasik masalı yeni bir kurguyla ve yeni bir olay örgüsüyle yeniden yorumlamaktadır (Üner, 2019). Filmin en dikkat çeken ve en çok tartışma yaratan yanı ise prensesin Afro-Amerikalı olmasıdır çünkü Walt Disney'ın Kül Kedisi, Pamuk Prenses ve Uyuyan Güzel gibi popüler karakterleri arasına ilk defa bir Afro-Amerikalı prenses girmektedir. Daha önceleri, rrkçllıkla ve toplum içinde yerleşmiş olumsuz önyargıları sürdürmekle sık sık eleştirilmiş olan Disney'in bu girişimi, geçmişteki tavrı nedeniyle çok tartışılmış ve filmi önemli bir adım olarak görenler olduğu gibi birçok yönüyle eleştirenler de olmuştur. Bu eleştiriler çoğunlukla filmin geçtiği mekâna ve karakterlerin temsil ettiği kimliklere odaklanmıştır (Barnes, 2009). Bu nedenle, öncelikle filmin geçtiği mekân, olay örgüsü ve karakterin genel özellikleri hakkında bilgi vermek isterim.

Klasik-geleneksel masalların aksine, bu anlatıda mekân ve zaman da önem taşır. Hikâye, 1920'li yıllarda ABD’nin New Orleans şehrinde geçmektedir. New Orleans, Mississippi Nehri'nin denizle buluştuğu bölgede kurulu, Afro-Amerikalı, Fransız ve İspanyol etkilerini bir arada barındıran, çok kimlikli bir şehirdir. Fransızlar tarafından kurulmuş, kısa bir süre İspanyol yönetiminde kalmış ve 1803 yllında ABD’ye satılmıştır. Caz müziğinin doğduğu yer olarak bilinen şehir, kendine özgü mutfağı ve Mardi Gras karnavalıyla da ünlüdür. Mardi Gras, Fransa'dan gelen ve ABD'de sadece New Orleans'ta kutlanan dini bir gündür. New Orleans, yaşadığı doğal felaketler nedeniyle büyük acılar çekmiştir. 2005 yılında şehri vuran Katrina Kasırgası, büyük bir kayba yol açmıştır. Kasırga sonrasında siyasiler ve medya tarafından verilen tepkilerin basmakalıp ayrımcı önyargıları sürdürmesi, kültürel ve siyasi eleştirileri de beraberinde getirmiştir.

Filmin yapımcılarından Peter Del Vecho, masalın bu yeni yorumunun nasıl ortaya çıktığını anlatırken New Orleans'ta geçecek ve şehrin "renkli geçmişini ve derin müzikal tarihini" yansitacak bir masal yaratmak istediklerini belirtir. Mekânın farklı kimlikleri bir araya getiren yapısı nedeniyle de filmde görülen çokkültürlü karakterleri oluşturduklarını ifade eder. Ana karakter Tiana'nın da "son derece

Tüm çeviriler makale yazarı tarafindan yapılmıştır. 
becerikli ve yetenekli” bir kahraman olduğunu, bir prens tarafından kurtarılmayı bekleyen alışıldık masal kahramanları arasına girmediğini vurgular. Bununla birlikte "Afro-Amerikalı kadınların özelliklerini taşımasını ve son derece güzel olmasını” istediklerini de belirtir (Del Vecho, alıntılayan Barnes, 2009).

Anlatının ana kahramanı Tiana, işçi sınıfından gelmektedir. Filmin açılış sahnesinde çocukluğundan sahneler izlediğimiz Tiana’nın babası birkaç işte birden çalışmaktadır ve annesi de terzilik yapmaktadır. New Orleans'in en zengin adamı olan Bay La Bouffe'un kızı Charlotte, Tiana'nın annesi Eudora'nın en iyi müşterisidir ve iki kız çok iyi arkadaştırlar. Tiana’nın ailesi zor şartlarda yaşıyor olsa da komşularıyla güzel ilişkiler sürdüren mutlu bir aile olarak betimlenmektedir. Tiana ve Eudora, akşam eve döndükleri zaman, Tiana'nın babası James ile beraber New Orleans mutfağına özgü bir yemek olan gumbo pişirirler. Bir gün kendi restoranını açma hayalı kuran babası, iyi yemeğin en önemli özelliğinin farklı hayatlar yaşayan insanları bir araya getirmesi olduğunu söyler. Tiana'nın çocukluğundan bir günü anlatan bu açlış bölümü, yemeğin de filmin ana unsurlarından biri olduğunu göstermesi açısından önemlidir. Bu kısa açılış bölümünden sonra Tiana'yı büyümüss olarak görürüz. Babası vefat etmiştir ve Tiana, babasının hayalinin peşinden koşarak çalıştığı restoranlardan kazandığı küçük paraları biriktirip bir gün kendi restoranını açmayı hayal etmektedir. Günün birinde Maldonya Prensi Naveen şehre gelir ve çocukluğundan beri bir prensle evlenmenin hayalini kuran Charlotte, Prens Naveen’i de davet edeceği büyük bir parti verir. Bu kutlamalar aynı zamanda geleneksel Mardi Gras şenliklerine denk gelmektedir. Charlotte, Tiana'dan, partide ikram edilmek üzere New Orleans mutfağına özgü "benye" adlı tatlıdan yapmasını ister. Bu işten kazandığı para sayesinde Tiana, hayalini kurduğu restoranı açmaya çok yaklaşır ancak partide işler beklendiği gibi gitmez. Prens Naveen ve uşağı Lawrence, partiye gelmeden önce bir vodoo büyücüsüyle pazarlık yaparlar ve her ikisini de kandıran büyücü, Naveen’i bir kurbağaya dönüştürür ve Lawrence’ı da Naveen’in görünümüne sokar. Kurbağaya dönüşen Naveen, partide Tiana ile karşılaşır. Hazırladığı benyelerin düşüp dağılması nedeniyle üstü kirlenen Tiana, Charlotte'un prenses kıyafetlerinden birini giymiştir. Bu nedenle Naveen onu bir prenses sanır ve Kurbağa Prens masalında olduğu gibi Tiana'dan kendisini öpmesini ister. Bunun karşılığında ona istediği restoranı açması için yardım edeceğini söyler ancak öpücük beklenenden farklı bir etki yapar. Kurbağa Prens yeniden insana dönüşeceğine Tiana bir kurbağaya dönüşür ve ikisi Louisiana bataklıklarında uzun bir maceraya atılır. Bu macerada hem iyi dostluklar kurarlar hem de nihayetinde birbirlerine âşı olduklarını anlarlar.

"Kurbağa Prens" masalının Grimm Kardeşler'den bugüne gelene kadar uğradığı dönüşümleri inceleyen Melda Üner, Tiana karakterinin "klasik-geleneksel olanın tam tersi" olduğunu savunur (Üner, 2019: 222) çünkü her şeyden önce "Bir masalda kadın karakterin erkeği uğradığı kötü büyüden kurtaracak öpücüğü vermesi pek nadir karşılaşllan bir durumdur” (Üner, 2019: 222). Üner, filmin “öteki” kavramını birçok açıdan sorguladığı yorumunda bulunur. Üner'e göre klasik masallardaki kadın karakterlerden farklı olan Tiana, bir "öteki”dir. Filmin arka planında yer alan Mardi Gras şenlikleri de "öteki”ni ortadan kaldıran bir unsurdur. Üner'e göre "Prenses ve Kurbağa” filmi, "toplum tarafından 'uygun'luğu kabul görmüş düşünceleri tartışır, izleyiciyi şaşırtır. 'Öteki’nin, alışlagelmiş algıdan farklı olarak yakın durduğunu gösterir. Hiyerarşik düzenin büyük oranda ylkıldığını vurgular” (Üner, 2019: 225). Fakat, filmle ilgili incelemelerin hepsi Üner’inki gibi olumlu değil. Filmi, yemek, kimlik ve ideoloji ekseninle ele alan Fabio Parasecoli, Disney'in ilk Afro-Amerikalı prensesi için çizilen karakterin, New Orleans'taki çatışmayı örttüğünü, sınıfsal ve etnik stereotipleri sürdürdüğünü savunur (Parasecoli, 2019). Bir sonraki bölümde, Parasecoli'nin filmle ilgili yorumları da takip edilerek filmde yemeğin üstlendiği roller incelenecektir. 


\section{“Prenses ve Kurbağa” filminde yemeğin rolü}

Filmde yemek kültürünün çok önemli bir rolü olduğu hem Tiana'nın bir restoran açma hayalinden hem de sık sık karşımıza çıkan yemek pişirme ve sunma sahnelerinden anlaşılabilir. Fakat yemek sadece beslenmeyle ilgili bir unsur olarak değil, kültürü ve insan ilişkilerini temsil eden bir öğe olarak öne çıkmaktadır. Filmi bu açıdan inceleyen Fabio Parasecoli, yemekle ilgili davranışların ve uygulamaların güçle, kültürel sermayeyle, sınıf statüsüyle, etnisiteyle ve toplumsal cinsiyetle bağlantılarına dikkat çekerek, ilk Afro-Amerikalı prenses olarak izleyici karşısına çıkan Tiana’nın ekrandaki görüntüsünü kolay kabul edilebilir bir şekle sokmak için yemeğin kullanıldığını ileri sürer (Parasecoli, 2010).

Parasecoli'ye göre Tiana, bir restoran sahibi olmayı hayal etse de sürekli yemek pişirirken gösterilir ve bu sayede, geleneksel olarak siyah kadınlarla özdeşleştirilen aşçılık işiyle meşgul olarak çıkarılır izleyicinin karşısına (Parasecoli, 2010: 452). Disney’in ilk Afro-Amerikalı prensesi, siyahlara özgü yemek işiyle uğraşır halde betimlenmektedir. Ayrıca, yine Parasecoli'nin dikkat çektiği üzere Tiana, diğer Disney karakterlerinin aksine çok çalışarak başarıya ulaşmayı hayal etmektedir. Bu da onu bir kez daha Afro-Amerikalıların geçmişine ve sınıfsal statüsüne bağlayan bir özelliktir. Tiana soylu değildir ve doğa üstü özellikleri de yoktur. Fakat yemek konusunda çok güçlü bir yeteneği vardır, bu da bedensel görünüşü açısından olmasa da davranış şekli ve doğal eğilimi açısından onu Afro-Amerikalı dadı stereotipine yaklaştıran bir özelliktir (Parasecoli, 2010: 459). Parasecoliye göre tüm bu özellikler, Tiana'yı ilk Afro-Amerikalı prenses olarak biraz daha kabul edilebilir kılacaktır: "Disney animasyonlarının ilk siyah kadın kahramanı, işçi sınıfı statüsünü doğrulayan kültürel yakıştırmalarla birlikte geliyor. Bu nedenle de ana akım izleyicilerin, bu siyah kadının toplumsal konumu hakkındaki beklentilerini ve peşin hükümlerini sarsmıyor" (Parasecoli, 2010: 459).

Parasecoli'ye göre yemek ayrıca New Orleans'taki kültürel çatışmaları perdelemek ve uyumlu bir atmosfer çizmek için kullanılır. Parasecoli, bu çerçevede, Louisiana mutfağının en bilinen yemeği olan gumbo'nun, bu filmde çok bileşenli bir topluluğun metonimisi olarak öne çıkarıldı̆̆ını belirtir (Parasecoli, 2010: 452). Gumbo yemeğinin özellikleri düşünüldüğünde, Parasecoli’nin bu yorumu anlamak kolaylaşır. Gumbo, Afro-Amerikalı, Kızılderili ve Avrupalı bileşenleri bir araya getiren, Louisiana'nın Kreol mutfağına özgü bir tür sulu yemektir. İsmini, Bantu dilinde "bamya" için kullanılan bir sözcükten almaktadır. Bamya, bu yemeye kıvam vermesi için kullanılan temel bir bileşendir ama bamya yerine kıvam verici olarak sassafras ağacının yapraklarından elde edilen bir baharat da kullanılabilir. Yemeğin tarifine göre, un ve yağ karıştırılarak kavrulduktan sonra içine soğan, sarımsak, yeşil biber, domates, çeşitli otlar ve baharatlar eklenir. Ayrıca deniz mahsulleri, tavuk, domuz eti, ördek katılabilir. Genellikle karides, yengeç ve istiridye kullanılsa da farklı malzemeler de tercih edilebilir (Encyclopaedia Britannica, 2018). Felicity Cloake, gumbo tariflerinin çok çeşitli olduğunu belirtir ve pişirmesi saatler alabilen bu yemeğin, tıpkı caz müziği gibi, doğaçlamaya çok açık olduğunu vurgular (Cloake, 2013). Disney'in, farklı etkileri içinde taşıyan ve tarifi değişkenlik gösterebilen bu yemeği, içinde bulunduğu toplumun bir metonimisi olarak ele almasının bu nedenle son derece anlaşılır olduğu söylenebilir. Parasecoli'ye göre gumbo, turistler tarafından çok iyi bilinen bir yemek olduğu ve sadece siyahlara ait olarak tanınan başka bazı yemekler kadar riskli olmadığı için tercih edilmiştir (Parasecoli, 2019: 463).

Parasecoli, filmde yemeğin oynadığı rolü açıklarken filmdeki tüm karakterlerin yemekten çok iyi anladıklarını ve bu özelliğin sanki Louisianalıların kültür mirasının ve hatta biyolojilerinin bir parçası olarak öne çıkarıldığını ifade eder. Hepsi aynı yemekleri afiyetle yerler. Bu sayede Louisiana’yı uzun yıllar boyunca şekillendiren toplumsal dinamikler ve kimlik politikası, sessizce gözlerden uzaklaştırılır 
ve yerine turistleri memnun edecek bir ziyafet yerleştirilir. İzleyiciler de etniler ve sinıflar arası bir mücadeleyi hatırlatmayan bir mekânı izler böylece (Parasecoli, 2019: 467).

Yemeğin kültürle ve ideolojiyle bu denli iç içe olduğu göz önünde bulundurulduğunda kültüre özgü yemek isimlerinin altyazı gibi birçok kısıtlamayı beraberinde getiren bir uğraş kapsamında nasıl aktarılacağı da ayrı bir tartışma konusu olarak kendini gösterir. İlerleyen sayfalarda "Prenses ve Kurbağa” filminin iki Türkçe altyazısı incelenecek, kültüre özgü yemek isimlerinin ve sevgi sözü olarak ya da deyimler ve yerleşik ifadeler içinde kullanılan yemek isimlerinin aktarımı sürecinde çevirmenler tarafından kullanılan stratejiler betimlenecektir.

\section{Kültüre özgü mutfak terimlerinin çevirisinde kullanılan yöntemler}

"Prenses ve Kurbağa" filminde, yemek isimlerinin farklı işlevlerle kullanıldığı görülmektedir. Bazı yemek isimleri, kültürle ve toplumla bağlantı kurmayı sağlarken, bazı yemek ya da yiyecek isimlerinin sevgi sözü olarak kullanıldığı cümleler de dikkat çekmektedir. Ayrıca içinde farklı yemek isimlerinin geçtiği deyimlerin ve kalıp ifadelerin de sık sık kullanıldığı gözlemlenmektedir. Makalenin bu bölümünde, öncelikle kültüre özgü yemek isimlerinin Türkçe karşıllkları incelenecektir. Ayrıca sevgi sözü olarak kullanılan yemek isimleri ve içinde yemek ismi geçen deyimlerin çevirileri de araştırılacaktır. $\mathrm{Bu}$ incelemede, herhangi bir eleme yapılmaksızın filmde geçen, yemekle ilgili tüm ifadeler incelenecektir. Bununla birlikte sadece yemek konusuna odaklanılacaktır ve altyazılar diğer yönlerden incelenmeyecektir. Örneğin lehçelerin aktarımı, sözcük oyunlarının yeniden üretilmesi, mizahi öğelerin çevirisi ya da altyazı tekniklerine dikkat edilip edilmemesi gibi konular tartışmanın dışında tutulacaktır. Öte yandan, yemekle ilgili öğelerin Türkçeye aktarımı incelenirken altyazı çevirisini diğer çeviri türlerinden ayıran özellikler ve bu çeviri türünün kendine özgü kısıtlamaları (maksimum satır ve karakter sayısı gibi) göz ününde bulundurulacaktır (Dỉaz Cintas, 2010; Okyayuz \& Kaya, 2016).

Yapılacak incelemede "Prenses ve Kurbağa" filminin, biri gönüllü olarak çevrilip internette paylaşılmış, biri de filmin Türkiye'de satışa sunulan yasal kopyalarında kullanılan iki Türkçe altyazısı incelenecektir ve çevirmenlerin yemekle ilgili sözlerin çevirisinde başvurdukları ödünç alma, açımlama, üst terim kullanarak genelleme yoluyla aktarma, başka bir yemek ismiyle yer değiştirme ve atlama gibi yöntemler örneklerle tartışmaya açllacaktır. Filmin internetten ücretsiz olarak ulaşılabilen altyazısı "nazo82 \& Shagrathian" imzasıyla paylaşılmıştır (Bu çeviri, bundan sonra "Birinci çeviri” olarak anılacaktır). Yasal versiyonun çevirmeni ise Murat Karahan olarak belirtilmektedir (Bu çeviri, bundan sonra "İkinci çeviri" olarak anılacaktır). "nazo82 \& Shagrathian", film ve diziler için yaptıkları altyazı çevirilerini internet ortamında paylaşırken Murat Karahan, 1992 yılından beri dublaj ve altyazı çevirisi yapan çok deneyimli, profesyonel bir çevirmendir. Boğaziçi Üniversitesi Çeviribilim Bölümü’nde eğitim almış ve daha sonra aynı bölümde yarı zamanlı olarak altyazı çevirisi dersleri vermiştir. Bu makale, kaynak ve erek metinlerin karşılaştırılmasına odaklanan, betimleyici bir yaklaşımı benimsemektedir. $\mathrm{Bu}$ nedenle çevirmenlerin yaşam öyküleri, kültür ve toplum içindeki konumları ve meslek algıları, ayrıntılı bir incelemeye tabi tutulmayacaktır. Çevirmenlerin toplum içindeki konumları ve kültürel bağlarının, konuya sosyolojik ya da işlevselci açılardan yaklaşacak farklı çalışmalarda incelenmesi, bu makale kapsamında sunulan betimleyici verileri güçlendirecek ve tamamlayacaktır.

"Prenses ve Kurbağa" filminin görsellerinde olduğu gibi diyaloglarında ve şarkılarında da yemek en belirgin öğedir diyebiliriz. Öne çıkan yemek isimlerinin başında ise "gumbo" gelmektedir. "Gumbo" sözcüğü İngilizce altyazılarda 11 kez geçmektedir. Birinci çeviride "gumbo" sözcüğünün 9 yerde "yahni” 
olarak çevrildiği, bir yerde atlandığı ve bir yerde de "bamya" olarak aktarıldığı görülüyor. İkinci çeviride ise tutarlı bir şekilde "gumbo" karşılığının kullanıldığı anlaşılıyor.

Önceki bölümde de açılklanmış olduğu gibi gumbo, Louisiana mutfağına özgü bir yemektir (Resim 1) ve çok çeşitli malzemelerin bir araya getirilmesiyle hazırlanır. Yemeğin ismi Bantu dilinde "bamya" anlamına gelen bir sözcükten türemiş olsa da bamya bu yemekte kullanılan malzemelerden sadece biridir, yemeğin ana malzemesi değildir ve sadece kıvam vermesi için kullanılır. Ayrıca, bamya kullanmadan da gumbo hazırlamak mümkündür. Bu nedenle "gumbo" dendiği zaman akla gelen "bamya" değildir. Ayrıca, daha önce de belirtildiği gibi gumbo, birçok malzemeyi bir araya getiriyor olması nedeniyle çokkültürlü bir toplumun metonimisi olarak da kullanılmaktadır. Bu nedenle "gumbo" sözcüğünün "bamya" olarak aktarılması hem metonimiyi ortadan kaldıracaktır hem de izleyicilerin yemeğin içeriğini akıllarında canlandırmalarını güçleştirecektir. Hatta Türk mutfağındaki bamya yemeklerini düşünmelerine de neden olabilir. Oysa bamya, Türk mutfağında özellikle öne çıkan ve tek başına tüm bir kültürü temsil edecek yemeklerinden biri değildir. Ayrıca belirli bir yemek isminin tutarlı olarak aynı şekilde çevrilmesi de önemlidir. Birinci çeviride 9 yerde "yahni” karşıllğı kullanılmışken neden sadece bir yerde "bamya"nın tercih edildiğini açıklamak güç.

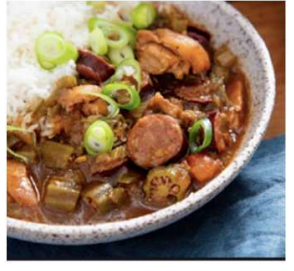

Resim 1: "Gumbo"

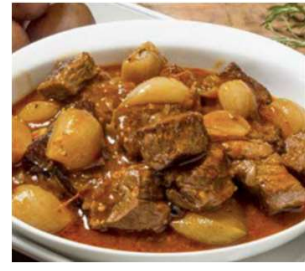

Resim 2: "Yahni"

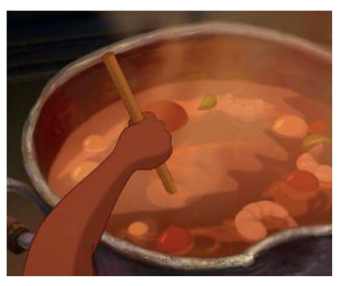

Resim 3: Filmde "Gumbo"

"Bamya” karşılığına kıyasla “yahni” karşılığının gumbo’ya daha yakın bir yemeği çağrıştırdığını söyleyebiliriz. Türkiye'de iyi bilinen yemeklerden biri olan yahni de aynı gumbo gibi sulu bir et yemeğidir (Resim 2). Çoğunlukla kırmızı etle yapılsa da tavuklu ve hindili tarifleri de bulunur. Ancak karides, yengeç gibi deniz ürünleri kullanılarak yapılan ve yaygın kullanılan bir yahni tarifi yoktur. Bu nedenle "gumbo"yu "yahni” olarak çevirmek öncelikle görselle altyazıların uyumu açısından bir karışıklık yaratmaktadır. Parasecoli'nin de belirtmiş olduğu gibi filmde yemekler çok gerçekçi ve rahatça tanınır şekilde resmedilmektedir (Parasecoli, 2010: 454). Örneğin Tiana'nın çocukluğunu anlatan giriş bölümünde, Tiana'nın babasıyla yemek yaptığı sahnede gumbonun içindeki karidesler açık seçik görülmektedir (Resim 3). Görseldeki yemeğin altyazıdaki adlandırmayla uyuşmaması izleyicinin aklını karıştırabilir.

Öte yandan altyazı çevirisinin kısıtlamaları da akıldan çıkarılmamalıdır. Düzyazıda kültüre özgü öğeleri aktarırken, gerekli görülmesi durumunda dipnot kullanımı ya da metin içi açıklama eklemek gibi yöntemlere başvurmak mümkünken altyazı söz konusu olduğunda bu yollara başvurmak yaygın bir yöntem değildir. Bu nedenle çevirmenlerin, filmi Türkçe altyazıyla izleyenlerin ve özellikle de çocukların rahatça anlayabileceği, en yakın Türkçe karşılığı tercih ettikleri anlaşılmaktadır. Louisiana mutfağına özgü bir yemek isminin Türk mutfağına özgü bir yemek ismiyle değiştirilerek çevrilmesi yaklaşımı, bir yerlileştirme (Venuti, 1998) olarak yorumlanabilir.

Kültüre özgü ögelerin aktarımı konusunda başvurulabilecek başka bir yöntem de ödünç almadır. İkinci çeviride de bu yola başvurularak "gumbo" karşılığının tercih edildiği ve her yerde tutarlı bir şekilde bu karşılığın kullanıldığı görülüyor. Başka kültürlere özgü sözcüklerin bir dilden başka bir dile olduğu gibi 
aktarılması, genellikle bir yabancılaştırma (Venuti, 1998) stratejisi olarak görülür. Yabancılaştırma, her şeyden önce kaynak metnin başka bir kültüre ait bir ürün olduğunu, başka bir toplumu tasvir ettiğini okura/izleyiciye hatırlatan bir yöntemdir. Ancak çok fazla sözcüğün ödünç alınması, erek metnin/filmin anlaşılmasını zorlaştırabilir. Burada incelenen filmde "gumbo" hem toplumun bir metonimisi olarak kullanıldığı hem de film boyunca sıkça sözü edilen bir yemek olduğu için kültüre özgü diğer yemeklerden daha özel bir konumdadır. Bu nedenle ödünç alma yoluyla aktarılması hem filmde anlatılan kültürün izleyici tarafından biraz daha yakından tanınmasına hem de bu kültürün bizim kültürümüzden farklı olduğunun anlaşılmasına yardımcı olacaktır. Çocuk izleyiciler açısından bakıldığında, yabancı bir sözcüğün onların aklını karıştırabileceği düşünülebilir fakat bu gibi ödünç sözcüklerin çok fazla olmaması durumunda onlar da filmi zorlanmadan takip edebilir, hatta diğer kültüre ilgi duymaya başlayabilir.

Gumbo'dan sonra filmde öne çıkan ikinci bir yiyecek de "beignet"dir. Yine Louisiana kültürüne özgü bir tatlı olan "beignet"nin ismi İngilizce altyazılarda 5 kez geçmektedir. Çevirilere bakıldığında, her iki çeviride de gumbo için kullanılan yaklaşımın tam tersinin tercih edildiği görülmektedir. Birinci çeviride "beignet” ödünç alma yoluyla "benye" olarak aktarllırken ikinci çeviride bu ismin "lokma" şeklinde, Türkiye'de daha çok bilinen bir tatlı ismi ile değiştirilerek çevrildiği görülmektedir. Bu durum, ilk bakışta, her iki çeviri açısından kendi içinde bir tutarsızlık olarak değerlendirilebilir. Birinci çeviride "gumbo" sözcüğü “yahni” şeklinde yerlileştirilerek aktarılırken "beignet" sözcüğü "benye" olarak ödünç alma yoluyla aktarılmıştır. İkinci çeviride ise "gumbo" ödünç alınırken "beignet", "lokma" olarak yerlileştirilmiştir. "Lokma" tercihi, pişirme yöntemi olarak benzerlik gösterdiği için tercih edilmiş olabilir. Her iki tatlı da hamurun kızartılması yoluyla yapılmaktadır fakat "benye" kare şeklinde hazırlanıp üzerine pudra şekeri dökülerek ikram edilirken lokma geleneksel olarak top ya da halka şeklinde hazırlanır ve sadece şerbete bulanmış olarak sunulur (Resim 4 ve Resim 5). Bu yerlileştirme de görselle diyaloglar arasında bir uyumsuzluk oluşmasına neden olur çünkü filmin çok ünlü bir sahnesinde Tiana'nın birkaç tabak benyeyi hızla pudralayarak çabucak servise hazır hale getirdiği görülmektedir. Bu tatlının hem şeklinin hem de sunuşunun lokmadan farklı olduğu açıcça görülür. Fakat, daha önce de belirttiğim gibi çok fazla ödünç alma, izleyicilerin filmi takip etmesini zorlaştırabilir. İkinci çeviride bu karşılığın kullanılmasının bir nedeni, özellikle çocuk izleyicileri yormama isteği olabilir.

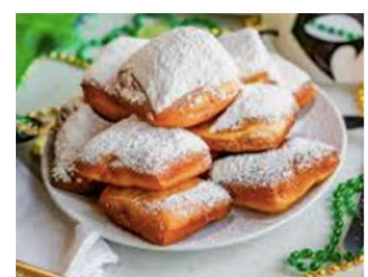

Resim 4: "Beignet"

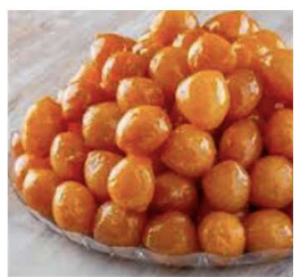

Resim 5: "Lokma"

Çevirmenlerin başvurdukları stratejileri daha iyi anlayabilmek için, özellikle öne çıan bu iki yiyecek dışındaki yemek isimlerinin çevirisinin de incelenmesi önemlidir. Tablo 1'de film boyunca geçen, kültüre özgü yemek isimlerinin listesi ve bunlar için iki farklı çeviride kullanılan karşılıklar sunulmaktadır. Liste, filmdeki akışs sırasını izleyecek şekilde düzenlenmiştir. 


\begin{tabular}{|l|l|l|}
\hline İngilizce & Birinci Çeviri & İkinci Çeviri \\
\hline Gumbo & Yahni (bir yerde “bamya”) & Gumbo \\
\hline Hush puppies & -atlanmış- & Tatlı \\
\hline Hotcake & Krep & Krep \\
\hline Flapjack & Gözleme & Kek \\
\hline Beignet & Benye & Lokma (bir yerde “tatlı") \\
\hline Étouffée & Fransız usulü karides & Deniz mahsulleri \\
\hline Jambalaya & Jambalaya & Jambalaya \\
\hline Red beans and rice & Barbunyalı pilav & Kuru fasulye - pilav \\
\hline Muffuletta & Muffuletta & Sandöviç \\
\hline Po' boy & Po' boy & Tost ekmeği \\
\hline Sauce piquant & Picante sosuyla & Domates sosu \\
\hline $\begin{array}{l}\text { Crawfish smothered in } \\
\text { remoulade sauce }\end{array}$ & Mayonezli kerevit & Mayonezli sosa bulanmış kerevit \\
\hline $\begin{array}{l}\text { Bananas foster sprinkled with } \\
\text { pralines }\end{array}$ & Kremalı, soslu muz & Çikolata parçacıklı muz tatlısı \\
\hline Tabasco & Acı sos & Acı sos \\
\hline Corn bread & -atlanmış- & Mısır ekmeği \\
\hline
\end{tabular}

Tablo 1: Filmde kullanılan kültüre özgü yemek isimleri ve çevirileri

Birinci çeviride "yahni" olarak yerlileştirme yoluyla çevrilen "gumbo" dışında "flapjack" isimli yiyeceğin de "gözleme" karşılı̆̆ı kullanılarak yine yerlileştirme yoluyla aktarıldığı görülüyor. "Flapjack" ve yine filmde de ismi geçen "hotcake", farklı kültürlerde değişik tariflerle pişirilen ve farklı şekillerde adlandırılan benzer yiyeceklerdir. Her ikisi de ince bir hamurun düz bir tavaya dökülerek pişirilmesiyle yapılır. İngilizcedeki "pancake", Fransızcadaki "crêpe" ve Türkçedeki "akıtma" da benzer yiyeceklerdir (Resim 6 ve 7). Genellikle tatlı olarak tüketilirler. İlk çeviride "flapjack"in Türkiye'de daha iyi tanınan bir yemek ismiyle değiştirilerek "gözleme" olarak çevrildiği ve yine benzer bir yiyecek olan "hotcake"in ise Fransızcadan Türkçeye geçmiş bir sözcük kullanılarak "krep” diye aktarıldı̆̆ı görülüyor. "Gözleme" hem görsel olarak hem de tarif olarak "flapjack"ten farklıdır (Resim 8). Fakat her ikisi de düz tavada ya da saçta pişirilir ve pratik yiyecekler arasında sayılabilir. Çevirmenlerin burada kaynak kültürü izleyiciye tanıtmak yerine izleyicinin biraz daha rahat anlayacağı bir karşllı bulmak istediği ve bu nedenle Türkiye mutfağında kolay pişirilen yemekler arasında yer alan "gözleme"yi tercih ettiği söylenebilir. "Hotcake" konusunda ise, Türkçeye Fransızcadan geçmiş "krep” sözcüğünü "akıtma”ya tercih ettikleri anlaşllyor. "Krep” sözcüğü artık Türkçede yaygın bir kullanım kazanmış olduğu için çevirmenlerin, hedef kitlelerinin bu karşllı̆̆ rahatça anlayacakları varsayımıyla tercih etmiş olduğu düşünülebilir. Öte yandan, filmin görsellerine bakıldığı zaman "flapjack" ve "hotcake" arasında büyük bir fark olmadı̆̆ı anlaşılır (Resim 9 ve 10). Bu nedenle her ikisini de "krep" olarak çevirmek de mümkün olabilirdi. İkinci 
çeviride de "hotcake"in yine "krep" olarak çevirildiği ve "flapjack"in "kek" olarak karşllandığı görülüyor. "Kek” de yine "krep” gibi daha önce ödünç alma yoluyla Türkçeye geçmiş ve yerleşmiş bir sözcüktür fakat Türkçedeki anlamıyla "kek", fırında pişirilen ve hamuru kabaran bir yiyecektir. Hem pişirme yöntemi hem de görüntü açısından “flapjack”ten farklıdır.

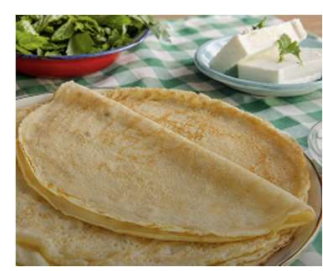

Resim 6: "Krep"

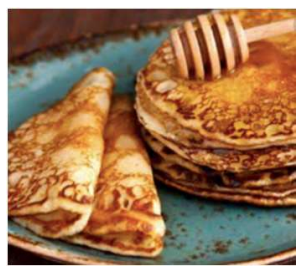

Resim 7: "Akıtma"

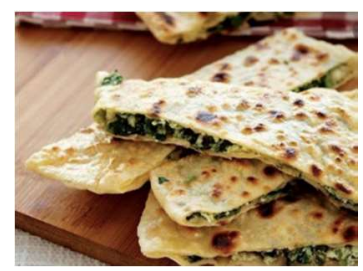

Resim 8: "Gözleme"

“Gumbo"yu "yahni”, "flapjack”i ise "gözleme” karşılıklarını kullanarak yerlileştirme yoluyla aktaran birinci çeviride ödünç alma da sıkça kullanılmıştır. "Benye” olarak aktarılan "beignet”ye ek olarak “jambalaya”, muffuletta”, "po’ boy” da ödünç alma yoluyla aktarılmıştır. Ayrıca "sauce piquant” da "picante sosu” olarak çevrilmiştir. "Sauce piquant”, Louisiana mutfağına özgü, domates kullanılarak yapılan, baharatlı bir sostur. "Picante sosu" da benzer bir şekilde domates ve baharat kullanılarak yapılır ancak daha özel bir isimdir. Pace markasının kurucusu David Pace, piyasaya sürdüğü acı domates soslarını bu şekilde adlandırmıştır. Burada çevirmenler sadece "acı sos" karşılığını kullanmak yerine farklı bir kültüre özgü bir tarifin söz konusu olduğunu vurgulayan bir karşıllğı tercih etmiş görünüyorlar. Fakat daha sonra geçen "tabasco" sosu, "acı sos" olarak aktarılmıştır ve burada kültürel farklara vurgu yapılmamıştır.

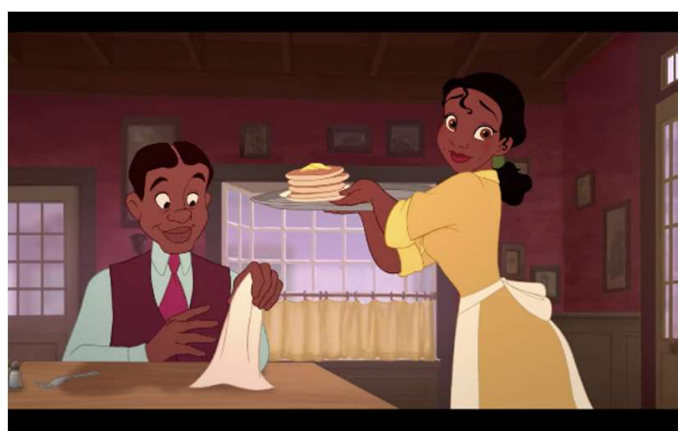

Resim 9: Filmde "hotcakes"

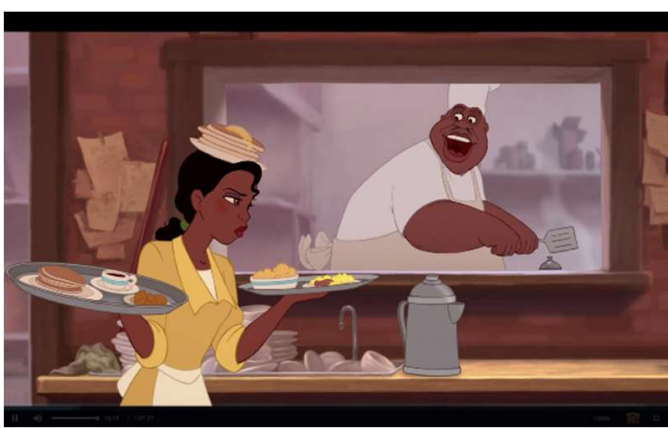

Resim 10: Filmde "flapjacks"

İkinci çeviride, ödünç alma yönteminin çok daha az kullanıldığı görülmektedir. Filmde özellikle öne çıkan yemek olan gumbo haricinde sadece "jambalaya" bu yöntemle aktarılmıştır. İlk çeviride ödünç alma yoluyla çevrilen "muffuletta", "po' boy” ve "sauce piquant”, burada benzer ürünlerle yer değiştirme yapılarak ve üst terim kullanılarak aktarılmıştır. "Muffuletta", "söndöviç" olarak çevrilmiştir. Muffuletta, ilk olarak New Orleans'a yerleşen İtalyan göçmenler tarafından yapılan, yuvarlak İtalyan ekmeğinin içine zeytin salatası, salam, jambon, peynir gibi ürünler konularak hazırlanan bir sandviçtir. Bu yiyeceğin isminin, üst terim kullanılarak genelleme yoluyla "sandöviç" olarak çevrilmesi, izleyicinin içeriği anlamasını kolaylaştırabilir ama "muffuletta" sözcügünün hemen ardından başka bir sandviç türü olan "po' boy” un da anılması nedeniyle aynı cümle içinde bu iki yiyeceğin arasındaki farkın belirtilmesi güçleşir. Belki de bu nedenle "po' boy”un “tost ekmeği” olarak aktarıldığı görülmektedir. Po' boy, genellikle rozbif ya da kızarmış deniz ürünleri kullanılarak hazırlanan, yine Louisiana’ya özgü bir sandviçtir. Sadece "tost ekmeği” olarak aktarıldı̆̆ zaman Louisiana mutfağına özgü yemeklerden söz 
edildiği bilgisi izleyiciye ulaşmaz. Çevirmenin yöntemini daha iyi anlayabilmek için, bu yemek isimlerinin geçtiği bağlama da dikkat etmek gerekir. Tiana, bataklıkta tanıştığı ve çok iyi arkadaş olduğu Louis isimli bir timsaha, açmayı hayal ettiği restorandan söz etmektedir. Louis de merakla, Louisiana'ya özgü "étouffée" isimli yemeğin de restoranda sunulup sunulmayacağını sorar. Tiana, Jambalaya ve gumbo gibi tüm yemeklerin olacağını söyleyince Louis, (ikinci çeviriyi izleyecek olursak) "Hep kuru fasulye - pilav, sandöviç ve tost ekmeği yemek istemişimdir” diye yanıtlar. Aralarında şöyle bir konuşma geçer:

İngilizce diyaloglar:

Louis: Now, this restaurant of yours,

is it going to have étouffée?

Tiana: Jambalaya, gumbo.

It's going to have it all.

Louis: I've always wanted to try red beans

and rice, muffulettas, po' boys.

Birinci çeviri:

- Senin restoranda Fransız usulü

karides de olacak mı? - Jambalaya, bamya...

- Hepsi olacak!

- Barbunyalı pilavı hep denemek istemişimdir.

- Muffuletta, po' boy-

İkinci çeviri:

Senin restoranda,

Deniz mahsulleri olacak mı?

Jambalaya, gumbo.

Hepsi olacak.

Hep kuru fasulye - pilav, sandöviç

ve tost ekmeği yemek istemişimdir.

Kuru fasulye - pilav, Türkiye'de çok sık yenilen ve çok sevilen bir yemektir. Bu yemeği özel tariflerle sunan restoranlar da vardır. Ama "sandöviç" ve "tost ekmeği" bir restoranın özel menüsünde bulmayı bekleyeceğimiz yiyecekler değildir. Bu nedenle bağlam dikkate alındığında bu karşılıkların biraz yadırgatıcı olduğu düşünülebilir. Fakat ikinci çeviride çevirmenin "gumbo" ve "jambalaya" haricinde ödünç alma yönteminden uzak durduğu dikkate alındığında, bu yaklaşımın yöntemsel olarak kendi 
içinde bir tutarlılık sunduğu söylenebilir. Çevirmenin yabancılaştırma yönteminden uzak durduğu ve daha kolay kabul edilebilir bir çeviri sunmayı amaçladığı anlaşılıyor.

İlgi çekici başka bir örnek, açımlama yoluyla çevrilen "étouffée” sözcügüudür. “Etouféé, Louisiana’da geliştirilmiş, Kajun ve Kreol mutfaklarına özgü bir tariftir. İlk çeviride bu yemek Türkçeye, "Fransız usulü karides" şeklinde bir açıklama eklenerek çevrilmiştir. Louisiana şehri, Fransızlar tarafından kurulmuş olsa da kendine özgü bir mutfak geleneği vardır. Bu nedenle Louisiana mutfağından bir tarifin "Fransız usulü” olarak adlandırılması yanıltıcıdır. Aynı yemek, ikinci çeviride "deniz mahsulleri” karşılığı kullanılarak genelleme yoluyla aktarılmıştır.

Filmde ismi geçen ve yine kültüre özgü başka bir yiyecek olan "remoulade sauce" ise, Fransa'da doğmuş, mayonezi temel alan bir sostur. Farklı ülkelerde değişik versiyonları kullanılır. Louisiana'da kullanılan "remoulade sauce", Fransa'dakinden farklı olarak beyaz tonlarında değil daha kırmızımsı, koyu bir renktedir. Bu sosun isminin her iki çeviride de Türkiye'de daha yaygın bilinen bir sos olan "mayonez" karşılı̆̆ kullanılarak aktarıldığı görülüyor. Yine filmde ismi geçen "banana foster" ise, New Orleans'a özgü, muz ve vanilyalı dondurma kullanılarak yapılan bir tatlıdır. Filmde "bananas foster sprinkled with pralines" olarak geçmektedir. "Praline", çikolatalı ya da karamelize fındık ya da badem parçalarını ifade eden bir terimdir. Bu tatlı birinci çeviride "kremalı, soslu muz" olarak, ikinci çeviride ise" çikolata parçacıklı muz" olarak aktarılmıştır. Her iki çeviride de ödünç alma yönteminin çok fazla kullanımından kaçınıldığı ve yiyecek isimlerinin olabildiğince izleyicinin anlayabileceği şekle getirilerek aktarıldığı görülmektedir.

Kültüre özgü yemek isimleri konusunda, her iki çeviride de çevirmenlerin birden fazla yönteme başvurduğu, kimi zaman ödünç alma, kimi zaman da Türk mutfağına özgü ya da Türk izleyicilerin daha aşina olabilecekleri düşünülen isimlerle yer değiştirme yoluna gittiği görülmektedir. Bazı yerlerde açımlamaya ya da üst terim kullanımına başvurdukları da gözlemlenmektedir. Ayrıca bazı yerlerde atlamalar da yapılmıştır. Örneğin birinci çeviride "Hush puppies" ve "corn bread" atlanmıştır. Bunlar ikinci çeviride "tatlı" ve "mısır ekmeği" olarak çevrilmiştir. "Hush puppies"in "tatlı" olarak çevrilmesi, üst terim kullanımına bir diğer örnek olarak değerlendirilebilir. Aşağıdaki paragraflarda, yemek ve yiyecek isimlerinin sevgi sözcüğü olarak ya da deyim ve kalıp ifadeler içinde nasıl kullanıldı̆̆ı ve bu yapıların Türkçeye nasıl aktarıldı̆̆ incelenecektir.

Yemekle ilgili isimler, başka birçok dilde olduğu gibi İngilizce ve Türkçede de sevgi ifade etmek için sık kullanılır. Türkçede "tatlım”, "şekerim”, "kurabiyem”, şekerparem” gibi seslenişler çoktur. İngilizcede de benzer şekilde "sugar", "honey", sweetie" gibi kullanımlar çok yaygındır. Filmde de benzer kullanımların oldukça sık geçtiği görülmektedir. "Sugar", "sugarplum”, "honey", "babycakes" sözleri öne çıkmaktadır. Bu sevgi sözlerinin, Türkçe altyazılarda da yine benzer ifadelerle karşılandı̆̆ı gözlemlenmektedir. Birinci çeviride "tatlım", "tatlışkom", "şekerim" sözleri dikkat çekerken bazı yerlerde yiyecek bağlantısı göz ardı edilerek "minik bebeğim”, "bebeğim”, "hayatım” gibi karşılıkların da kullanıldığı görülmektedir. Ancak bu tercih bir kayıp olarak yorumlanamaz çünkü yemekle ilgili göndermeler, birebir karşılıklarla olmasa da yakın ifadelerle her iki çeviride de sık sık kullanılmıştır. Zaten her dilin sevgi sözcükleri farklı olduğu için bu gibi değişikliklerin olması son derece normaldir. İkinci çeviride de benzer kullanımlar dikkat çekiyor. "Tatlım", "kurabiyem", "şeker", "balım" gibi ifadeler, bu çeviride özellikle öne çıkıyor. Bununla birlikte bazı yerlerde yiyeceklerle bağlantı kurmak yerine "güzel kızım”, “canım”, "şirin şey” gibi karşılıklar da kullanılmış. İlk çeviride olduğu gibi bu çeviride de bu kullanımlar son derece doğal durmakta ve herhangi bir kayba neden olmamaktadır. 
İçinde çeşitli yemek isimleri geçen deyimler ve kalıp ifadeler de filmde sıkça kullanılmıştır. Diller arası çeviride deyimlerin sözcüğü sözcüğüne çevrilmesi yerine, benzer deyimlerle karşılanması önerilir. Bununla birlikte, kimi zaman deyimlerin içindeki sözcükler de çağrışımları nedeniyle önemli olabilir. Bu filmde, yemek öne çıkan bir tema olduğu için, içinde yemek isimleri geçen deyimler ve yerleşik kalıplar böyle bir değer kazanıyor. Filmin İngilizce diyaloglarında geçen "the egg is on your face", "Now we are cooking!", "Sucking on silver spoon", "Cheese and crackers!", "Give us a little sugar" gibi ifadeler bunlara örnek olarak gösterilebilir. Bu gibi ifadeleri çevirirken, çevirmenlerin hem benzer anlamı veren Türkçe deyimler ya da kalıplar bulması hem de buldukları alternatiflerin arasından, içinde yemek ismi geçenleri tercih etmesi bir çözüm olabilir. Elbette bu gibi alternatifler her zaman bulunamayabilir. Yukarıda verilen örneklerin pek çoğu, Türkçe çeviride sadece benzer anlamı veren ancak yemekle bağlantısı olmayan karşılıklarla aktarılmıştır. Bir istisna, "sucking on silver spoon" ifadesinin çevirisidir. $\mathrm{Bu}$ çeviriye biraz daha yakından bakmak isterim.

Tiana ve Prens Naveen, ilk tanıştıkları zaman birbirlerini pek sevmezler. İşçi sınıfından gelen Tiana hayatı boyunca hep çalışmıştır, Prens Naveen ise hep gülüp eğlenmiştir. Tiana, Naveen’in şımarıklığından söz ederken "Sucking on a silver spoon" ifadesini kullanır. Bu ifade birinci çeviride "kuş sütleriyle beslenmek", ikinci çeviride ise "gümüş tabaklardan yemek yemek" olarak aktarılmıştır. Birinci çeviri, benzer bir anlamı ifade edecek ve yine içinde yemek geçen Türkçe bir deyim kullanırken ikinci çeviride kaynak dildeki "silver spoon" / "gümüss tabak" ifadesi olduğu gibi alınmıştır. Her iki çeviri de Türkçe anlatıma uygun, anlamı açık ve yemek bağlantısını koruyan ifadeler sunmaktadır. Başka bir alternatif de "bir eli yağda bir eli balda" deyimini kullanmak olabilirdi. İçinde yemek ya da yiyecek ismi geçen diğer ifadeler ve her iki çevirideki karşıllkları Tablo 2'de verilmektedir.

Önceki sayfalarda da belirtildiği gibi, yerleşik kalıpların hem anlamını hem de içinde kullanılan sözcüklerin yarattığı çağrışımlarını aktarmak her zaman mümkün olmayabilir. Tablo 2'de görüldüğü üzere, her iki çeviride de çevirmenler öncelikle anlama ve anlaşılırlı̆a odaklanmış, yemek isimleri kullanmayı bir öncelik olarak görmemişlerdir. "Sucking on silver spoon” örneği dışında sadece bir yerde daha bir yiyecek isminin kullanıldığı görülüyor. "Cheese and crackers!" ifadesinin çevirinde, birinci çeviri sadece anlama odaklanarak "Hay aksi!" karşıllğını önerirken ikinci çeviride "Hay bin kraker!" karşılığı verilerek "kraker" sözünün de çeviriye aktarıldığı görülüyor. Burada, Tenten'in Türkçe çevirilerinde Kaptan Haddock'un sıkça kullandığı "Hay bin kunduz" ifadesinin bir versiyonu üretilerek hem içinde yiyecek adı geçen bir ifade kullanılmış hem de şaşkınlık ve kızgınlık ifadesi yaratıı bir çözümle anlatılmıştır.

\begin{tabular}{|l|l|l|}
\hline İngilizce & Birinci çeviri & İkinci çeviri \\
\hline Everything looks peachy-keen & Her şey harika görünüyor & Her şey harika görünüyor \\
\hline $\begin{array}{l}\text { Well, the egg is on your face, all } \\
\text { right? }\end{array}$ & Asıl tufaya düşen sensin & $\begin{array}{l}\text { Hadi ya. Yine de büyük bir yanılgı } \\
\text { içndesin, } \\
\text { tamam mı? }\end{array}$ \\
\hline Now we are cooking! & Hazır ve nazırız! & İşte şimdi oldu! \\
\hline Sucking on a silver spoon & Kuş sütleriyle beslenip & Gümüş tabaklardan yemeklerini yiyip \\
\hline Cheese and crackers! & Hay aksi! & Hay bin kraker! \\
\hline
\end{tabular}




\begin{tabular}{|l|l|l|}
\hline Give us a little sugar, now. & $\begin{array}{l}\text { Ölçüsünü ayarladın, değil } \\
\text { mi canım? }\end{array}$ & Biraz öp bakalım. \\
\hline Give your lovely bride some sugar! & Gelini öp de görelim. & Şu güzel geline bir öpücük ver. \\
\hline \multicolumn{2}{|r|}{ Tablo 2: İçinde yiyecek ismi geçen kalıp ifadeler ve çevirileri } \\
\hline
\end{tabular}

\section{Sonuç}

Bu makalede, 2009 Walt Disney yapımı “The Princess and the Frog” filminin iki Türkçe altyazısı kültüre özgü yemek isimlerinin çevirisine odaklanarak incelenmiştir. Ayrıca sevgi sözü olarak kullanılan yemek isimlerinin çevirisi ve içinde yemek isimleri geçen deyimlerin ve kalıp ifadelerin çevirisi de incelemeye alınmıştır. Filmin seçilme nedeni, yemekle kültürün ilişkisini çok güzel ortaya koyan bir örnek sunması ve yemeğin de filmde öne çıan aktörlerden biri olmasıdır. İncelemede filmin çeviri açısından düşündürücü örnekler ortaya koyduğu görülmüştür. Ele alınan her iki çeviride de çevirmenlerin birden fazla yöntemi bir arada kullandığı anlaşılmıştır. Bu yöntemler arasında ödünç alma, üst terim kullanarak genelleme yoluyla aktarma, açımlama, başka bir yemek ismiyle değiştirme ve atlama özellikle öne çıkmaktadır. Birinci çeviride ödünç alma yönteminin daha sık kullanıldığı, ikinci çeviride ise bu yönteme olabildiğince az başvurulduğu anlaşılmıştır. Yemek, kültürle çok sıkı bir bağ içinde olduğu için yemek isimlerinin farklı yemek isimleriyle değiştirilerek aktarılması anlatının kültürle olan ilişkisini zayıflatabilir. Bu nedenle ödünç alma yöntemi, kültürler arasındaki farkları belirgin kılmak ve kaynak dilde yemek ile kültür arasında kurulan ilişkiyi aktarmak açısından başvurulabilecek bir yaklaşımdır. Fakat çok fazla terimin ödünç alınması altyazının takibini zorlaştırabilir ve izleyicilerin hikâyeden kopmasına neden olabilir. Özellikle küçük izleyiciler düşünüldüğünde, altyazıda ya da dublajda çok fazla ödünç sözcüğün yer almasının önemli bir güçlük oluşturacağı söylenebilir. Bu nedenle her iki çeviride de bu yöntemin sınırlı sayıda sözcük için kullanıldığı görülmektedir. Yapılan inceleme, Michael Cronin'in de belirtmiş olduğu gibi, yemek çevirisi söz konusu olduğunda benzer ama yine de farklı yemekler arasındaki ayrımı kavrayabilmek ve sofraya konan yemeğin bir kültür içindeki değerini görebilmek için biraz durmak ve yavaşlamak gerektiğini gösteriyor.

\section{Kaynakça}

Barnes, B. (2009). Her Prince Has Come. Critics, Too. The New York Times. https://www.nytimes.com/2009/05/31/fashion/31disney.html, (Erişim tarihi 15 Aralık 2019).

Barthes, R. (1961). Pour une psycho-sociologie de l'alimentation contemporaine. Annales 16 (5), 977986.

Beyaz, E. (2017). Representing Turkish Food History and Food Culture Through Translation: A Case of Turkish Confectionery. Yayımlanmamış Yüksek Lisans Tezi. Dokuz Eylül Üniversitesi, İngilizce Mütercim-Tercümanlık Yüksek Lisans Programı.

Bourdieu, P. (1979). La Distinction: Critique sociale du jugement. Paris: Editions de Minuit.

Chiaro, D. (2008). A taste of otherness eating and thinking globally. European Journal of English Studies, 12 (2), 195-209.

Chiaro, D. \& Rossato, L. (2015). Food and Translation, Translation and Food. The Translator, 21 (3), 237-243.

Ciribuco, A. (2019). How do you say kélén-kélén in Italian? Migration, landscape and untranslatable food. Translation Studies, DOI: 10.1080/14781700.2019.1662837 
Counihan, C. \& Van Esterik, P. (2013). Why Food? Why Culture? Why Now? Introduction to the Third Edition. C. Counihan \& P. Van Esterik (Der.) Food and Culture, A Reader içinde (ss.1-15). New York: Routledge.

Cronin, M. (2015). The moveable feast: translation, ecology and food. The Translator, 21 (3), 244-256.

Cronin, M. (2017). Eco-Translation. Translation and Ecology in the Age of the Anthropocene. London: Routledge.

De Marco, A. (2015). Are green-lipped mussels really green? Touring New Zealand food in translation. The Translator, 21 (3), 310-326.

Dīaz Cintas, J. (2010). Subtitling. Y. Gambier ve L. van Doorslaer (Der.), Handbook of Translation Studies 1 içinde (ss. 344-349). Amsterdam: John Benjamins Publishing Company.

Encyclopaedia Britannica. (2018). Gumbo. https://www.britannica.com/topic/gumbo, (Erişim tarihi 15 Aralık 2019).

Garzone, G. (2017). Food, culture, language and translation. Journal of Multicultural Discourses, 12 (3), 214-221

González-Vera, P. (2015). Food for Thought. The Translation of Culinary References in Animation. İkala, the Journal of Language and Culture, 20 (2), 247-264.

Levi-Strauss, C. (1966). Le Triangle culinaire. L'Arc 26: 19-29.

Okyayuz, A. Ş. \& Kaya, M. (2016). Altyazı Çevirisi Eğitimi İçin Bir Model Önerisi. International Journal of Languages' Education and Teaching, 4 (2), 257-275.

Oster, U. \& Molés-Cases, T. (2016). Eating and Drinking Seen Through Translation: A Study of FoodRelated Translation Difficulties and Techniques in a Parallel Corpus of Literary Texts. Across Languages and Cultures 17 (1): 53-75.

Parasecoli, F. (2010). A Taste of Louisiana: Mainstreaming Blackness Through Food in The Princess and the Frog. Journal of African American Studies, 14: 450-468.

Rossato, L. (2015). Le grand culinary tour: adaptation and retranslation of a gastronomic journey across languages and food cultures. The Translator, 21 (3), 271-295.

Stano, S. 2016. Lost in translation: Food, identity and otherness. Semiotica 211: 81-104.

Üner, M. (2019). Klasikten Postmoderne Bir Masalın Müthiș Serüveni: Kurbağa prens, Kurbağa Prenses, Prenses ve Kurbağa. Türklük Bilimi Araştırmaları Dergisi, TÜBAR 45: 209-225.

Venuti, L. (1998). Strategies of Translation. M. Baker \& K. Malmkjær (Der.), Routledge Encyclopedia of Translation Studies içinde (ss. 240-244). London: Routledge.

Vidal Claramonte, M. Á. ve Faber, P. (2017). Translation and food: the case of mestizo writers. Journal of Multilingual Discourses, 12 (3), 189-204. 